\title{
Intracranial Dural Sinus Thrombosis: Novel Use of a Mechanical Thrombectomy Catheter and Review of Management Strategies
}

\author{
Shah-Naz Hayat Khan, MD, FRCSC; Opeolu Adeoye, MD; Todd Anthony Abruzzo, MD; \\ Lori A. Shutter, MD, PT and Andrew Joel Ringer, MD
}

\begin{abstract}
Management of intracranial dural sinus thrombosis with involvement of multiple sinuses is complex, often involving not only the primary problem (thrombosis) but acute adverse events consequent to the disease. We highlight the novel use of an endovascular device (typically for suction thrombectomy in the peripheral vascular system) used in our patient with a life-threatening multi-sinus thrombosis. As there is no standard treatment yet for cranial sinus thrombosis, our review of the literature highlights some effective management strategies. A 35-year-old woman developed associated complications of cranial sinus thrombosis that included intracranial hypertension caused by an expanding intracranial hematoma, pulmonary embolism treated by placement of filters in superior and inferior vena cava to eliminate intra- and extracranial sources of emboli, and procedure-related retroperitoneal hematoma that necessitated peripheral vascular intervention. After failure of several common devices during mechanical thrombolysis, a thrombectomy catheter (typically for peripheral vascular intervention to aide in the clot removal) was used. Our case highlights the fine balance of anticoagulation and thrombolysis and the proactive, aggressive approach used by our multispecialty team to manage concurrent factors.
\end{abstract}

Keywords: Dural sinus thrombosis; endovascular; pulmonary embolism;

retroperitoneal hematoma; rt-PA; thrombolysis

Corresponding Author:

Shah-Naz H. Khan, MD

Cerebrovascular and Skull Base Surgery Program

Department of Surgery

Division of Neurosurgery

St. Louis University, School of Medicine

3635 Vista Avenue at Grand Boulevard

St. Louis, MO 63/I0-0250

Tel.: 3|4-577-87|5

Fax: $3|4-268-506|$

E-mail:drkhan@sasktel.net

Received: January 21, 2009

Revised: April 16, 2009

Accepted: April 29, 2009

doi: $10.3121 / \mathrm{cmr} .2009 .847$
$\mathrm{T}$

hrombosis of multiple cranial venous sinuses has a high mortality ranging from $38 \%$ to $53 \%$ even with treatment, especially when the patient presentation is stupor or coma. ${ }^{1,2}$ Medical treatment for this condition includes anticoagulation or local thrombolysis, which raises concerns about the associated high risk of intracerebral hemorrhage. The standard treatment for cranial sinus thrombosis has yet to be established. ${ }^{3-5}$ We describe a complicated case of multiple cranial sinus thrombosis that was successfully treated by chemical, mechanical and operative intervention. We highlight the novel use of an endovascular device typically used for suction thrombectomy in the peripheral vascular system and describe how a multidisciplinary team approached a treatment of the disease and its associated complications.

\section{Illustrative Case}

A 35-year-old obese woman on oral contraceptives presented to an outside institution complaining of the worst headache of her life. Findings on computed tomography (CT) scan and lumbar puncture were interpreted as normal. After being discharged home, she returned 2 days later with headache, confusion and a 

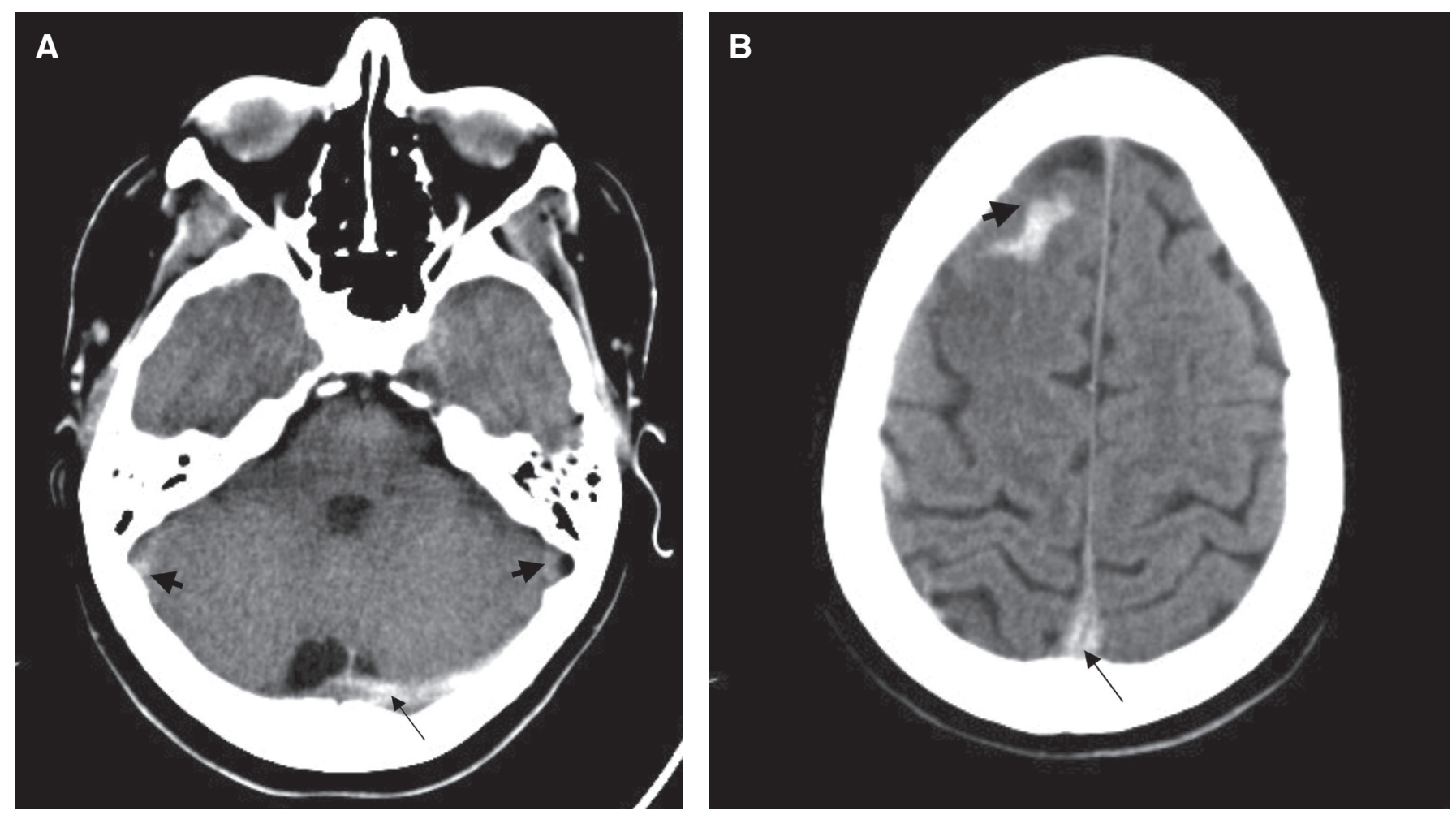

Figure 1. Non-contrast axial computed tomography (CT) scans demonstrating multiple sinus thrombosis. (A) Hyperdense left transverse sinus and torcula herophili (long arrow) are consistent with the presence of thrombus. Sigmoid sinuses (short arrow) are similarly affected. A higher cut (B) demonstrates a right frontal venous hemorrhagic infarct (short arrow), as well as superior sagittal sinus thrombosis (long arrow).

declining level of consciousness. Repeat CT scan was consistent with multiple cranial venous sinus thrombosis and venous hemorrhagic infarction of the right frontal lobe (figure 1). Findings of cranial sinus thrombosis were also corroborated by magnetic resonance venography that demonstrated the involvement of multiple sinuses and essential cortical veins (figure 2). The patient was intubated for airway protection and transferred to our institution.

On arrival, the patient had a Glasgow Coma Scale (GCS) of 8 (7 with intubation). She was admitted to the intensive care unit for medical stabilization and supportive care. Normal values were noted on hypercoagulability workup, which included proteins $\mathrm{C}$ and $\mathrm{S}$, anti-thrombin III, factor V Leiden, anti-lupus antigen, and anti-cardiolipin. An intracranial pressure monitor was inserted and anticonvulsants were initiated prophylactically. On re-evaluation, the results of the CT scan performed during her first hospital visit were consistent with cranial sinus thrombosis (figure 3). Cerebral angiography corroborated the findings of magnetic resonance venography, specifically complete occlusion of superior and inferior sagittal and straight sinuses. Occlusion was also seen in the transverse-sigmoid sinuses and the veins of Trollard and Labbé (figure 4). Mechanical thrombolysis was planned.

\section{Procedure}

A sheath was placed in the right femoral artery for catheterization of the left common carotid artery for angiography. A 7 French sheath was placed in the right femoral vein for intervention. A 7 French balloon-tipped guide catheter was introduced over a glide wire and positioned in the left jugular bulb. A Merci microcatheter (Concentric Medical, Mountain View, CA) was introduced through the venous sheath over a headliner wire using roadmap guidance from a retrograde venous injection from the jugular bulb. After removal of the microwire, the injection of the microcatheter demonstrated an absence of antegrade flow through the sagittal sinus to the torcula. The Merci L6 retriever device was prepared and advanced under fluoroscopic visualization to the superior sagittal sinus. Once deployed, the device was torqued and pulled back into the guide catheter while continuous suction was applied. The balloon guide catheter in the jugular bulb was kept inflated during Merci retriever deployment to minimize the risk of pulmonary embolus. Only a small amount of clot was noted on the retriever device. When the L6 device appeared deformed and could not be reloaded, it was replaced with a Merci X6 retriever device. The microcatheter was readvanced over the Headliner wire into the superior sagittal sinus, again with moderate difficulty. This X6 device was deployed with the balloon inflated on the guide catheter tip. After removal of the $\mathrm{X} 6$ device, the guide catheter was again copiously aspirated and flushed and then the balloon was deflated. A third attempt at mechanical thrombolysis was then made. Although angiography demonstrated persistent occlusion of the sinuses, after each attempt, a greater ease of catheter and device 
passage through the sinus was noticed, suggesting some recanalization. However, the amount of clot extracted was negligible.

In order to attempt chemical thrombolysis, we exchanged the 7 French guide catheter for a 5 French Envoy (Cordis, Miami Lakes, FL) guide catheter. With a microcatheter positioned in the mid superior sagittal sinus, recombinant tissue plasminogen activator (rt-PA) was infused through it at a rate of $4 \mathrm{mg} /$ hour. The patient remained intubated and was transported back to the neurosurgery intensive care unit.
Postoperative Course, Day 1

The patient appeared to respond well to the treatment administered. Intracranial pressure was $<20 \mathrm{~mm} \mathrm{Hg}$, and she followed commands with the right side; the left side was hemiparetic. Later that morning, she deteriorated neurologically as her level of consciousness declined and her intracranial pressure increased transiently to $80 \mathrm{~mm} \mathrm{Hg}$. Rapid intervention included administration of 3\% hypertonic saline to maintain intracranial pressure $<20 \mathrm{~mm} \mathrm{Hg}$ and cerebral perfusion pressure $>60 \mathrm{~mm} \mathrm{Hg}$. CT scan showed an expansion in the right frontal hematoma, prompting

Figure 2. Magnetic resonance venography in (A) coronal, $(B)$ left lateral, $(C)$ right lateral and (D) axial views, demonstrating the absence of major sinuses and essential cerebral veins.
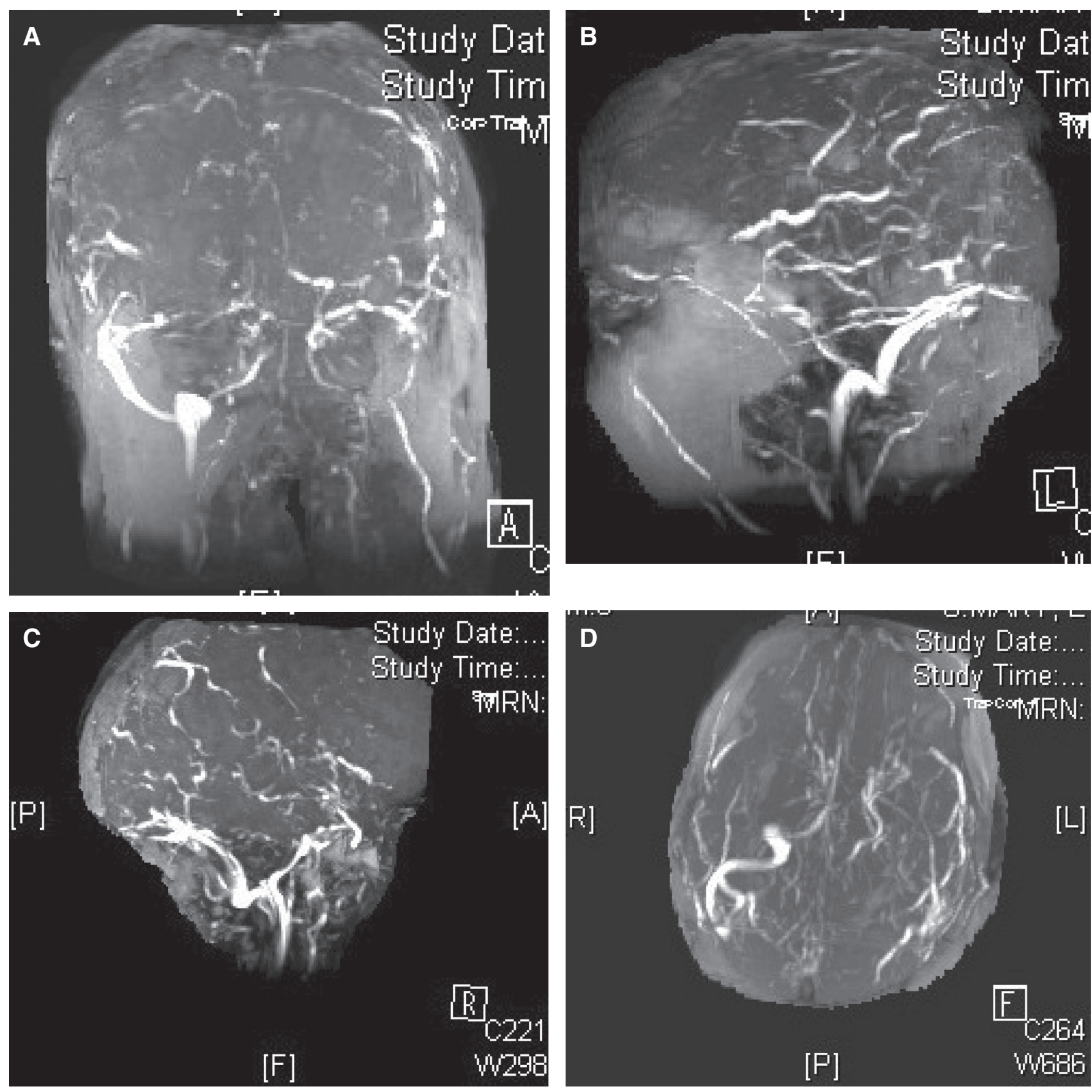

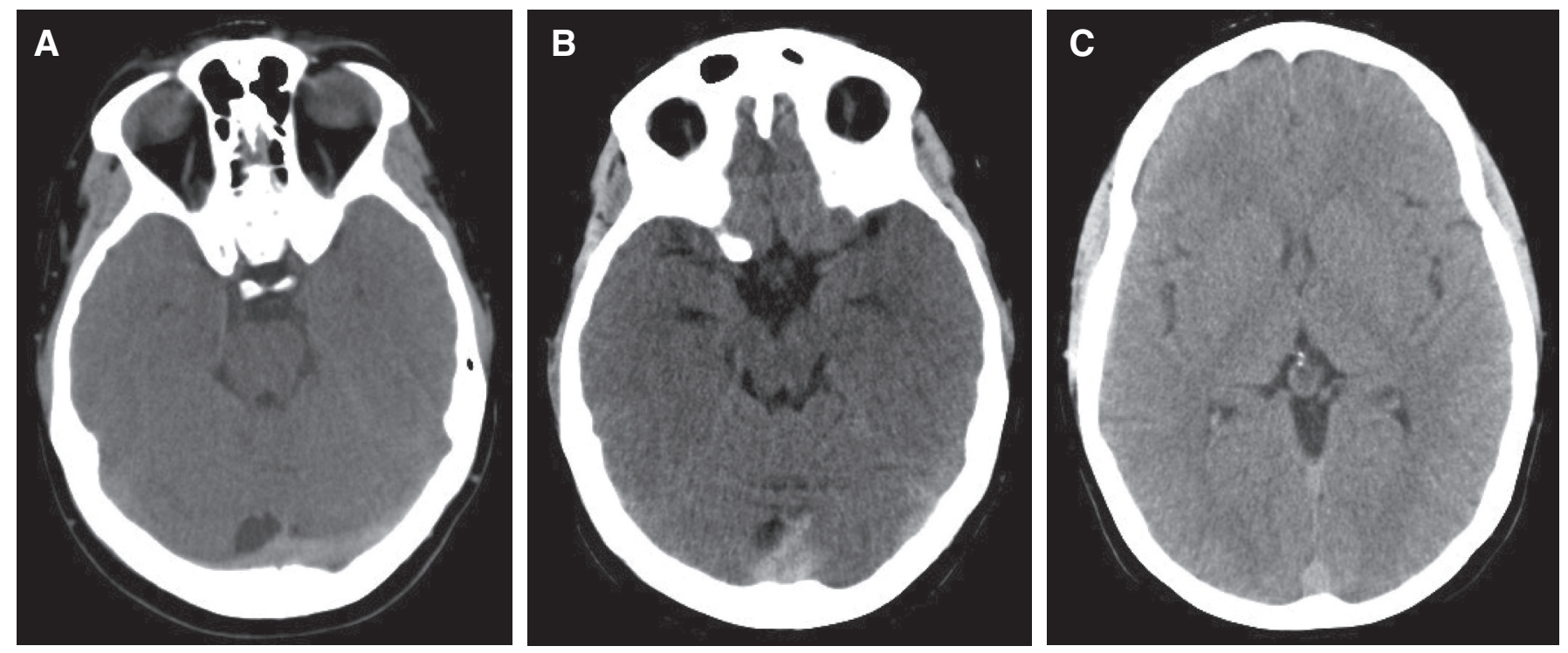

Figure 3. Non-contrast axial CT scans (A-C) obtained at time of the onset of the patient's symptoms were initially interpreted as normal. However, "rewindowing" makes cranial sinus thrombosis obvious. The only difference from her second CT scan (see figure 1) was the absence of right frontal venous hemorrhage. This example highlights the importance of meticulous examination of neuroimages to avoid missing diagnosis.

discontinuation of the rt-PA infusion. While awaiting reversal of the rt-PA, repeat angiography to assess the feasibility of further intervention revealed a significant recanalization of the superior sagittal sinus, right transverse and sigmoid sinuses, and jugular bulb (figure 5A and 5B). The left transverse sinus and ensuing distal outflow remained occluded. We reattempted mechanical thrombolysis, which would then be followed by craniotomy for decompression and hematoma evacuation. Despite repeated attempts at clot aspiration with an Angiojet (Possis Medical, Minneapolis, MN), its advancement was impossible beyond the sigmoid sinus. We then tried a 5 French Pronto V3 thrombectomy catheter (Vascular Solutions, Inc. Minneapolis, MN), which is a direct aspiration catheter commonly used for dialysis fistula thrombectomy. After the Pronto catheter was successfully positioned in the proximal left transverse sinus near the torcula, it was withdrawn while maintaining constant suction. The first attempt resulted in a very reasonable amount $(10 \mathrm{cc})$ of clot retrieval. A second attempt removed a small amount of additional clot. An angiogram at this point showed partial recanalization of the left transverse sinus; the left sigmoid sinus and internal jugular vein became visible (figure 5C).

After completion of thrombolysis, the patient was transferred to the operating room where a generous frontotemporal craniectomy and partial evacuation of right frontal intracerebral hematoma were performed.

\section{Postoperative Course, Days 2-7}

The patient's neurological examination improved to include brisk localization on motor exam. Routine Doppler sonography of the lower extremity revealed a deep vein thrombosis of the left common femoral vein. Because of her recent surgery and intracerebral hemorrhage, we believed that anticoagulation was contraindicated and placed a filter into the inferior vena cava. In the following days, the patient was examined for a bleeding source because of recurring anemia (hemoglobin $<7.0 \mathrm{~g} / \mathrm{dL}$ ) that necessitated multiple blood transfusions. Although Doppler ultrasonography of the femoral vessels was unremarkable, a CT scan of the abdomen was consistent with retroperitoneal hematoma and a possible pseudoaneurysm. She was managed conservatively until day 6 , when pulmonary difficulties developed. CT of the abdomen and CT pulmonary angiography revealed expansion of the retroperitoneal hematoma and multiple filling defects of the arteries of the left lower lobe that were consistent with pulmonary emboli.

Persistent difficulties maintaining adequate hemodynamic parameters with medical management continued. Therefore, a vascular surgery consultation was requested for potential surgical repair of the pseudoaneurysm. Filter placement into the superior vena cava filter was also considered to eliminate the likelihood of the intracranial venous sinus thrombosis as a source of pulmonary embolism. Consequently, when no abnormality was found, the right femoral vessels were exposed under direct vision and a micropuncture needle was used to obtain access. Arterial and venous angiography proved to be entirely unremarkable; images showed a patent aorta, iliac and femoral vessels with no aneurysm or extravasation, and patent venous system with no evidence of thrombus or extravasation. A Tulip jugular filter (Cook, Indianapolis, IN) was placed in the superior vena cava to exclude the intracranial venous sinuses as a source of pulmonary emboli.

The patient progressively recovered and was extubated on day 7. Neurological examination continued to improve as she became alert, oriented, and able to follow commands. She had 

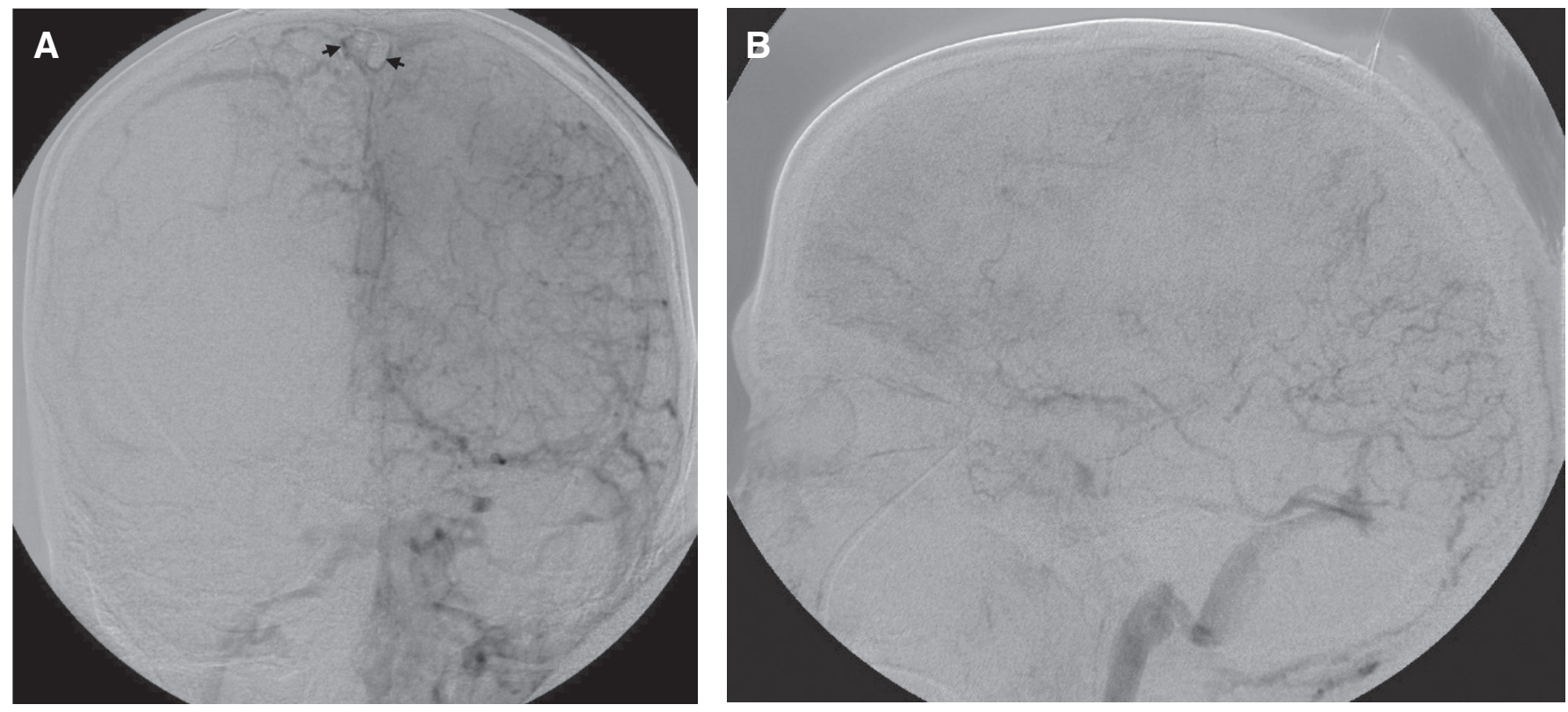

Figure 4. Cerebral angiography before intervention. (A) Anteroposterior and (B) lateral views corroborate the findings of magnetic resonance venography. Major sinuses and veins are conspicuously absent. Thrombosed superior sagittal sinus is highlighted by a thin rim of contrast surrounding clot in the lumen (arrows) in (A).

a significant left hemiparesis with hemineglect. She was transferred to a rehabilitation facility on long-term anticoagulation therapy with warfarin.

\section{Discussion}

The presence of intracerebral hemorrhage complicated the management of cranial sinus thrombosis in our patient. Additionally, the involvement of deep venous system portended a poor prognosis, demanding expeditious definitive intervention in a young patient. 6,7 After the failure of several common devices during mechanical thrombolysis, we used a thrombectomy catheter most commonly used in peripheral vascular intervention to aide in the removal of the clot. As there is no standard treatment yet for cranial sinus thrombosis, our review of the literature highlights some effective management strategies.

Cranial sinus thrombosis is an uncommon condition affecting about 5 to 8 patients annually at tertiary care centers. ${ }^{8,9}$ With its incidence peaking during the third decade, considerable handicap and loss of productivity occur. ${ }^{6,9}$ Since the diagnosis is often missed during the initial stages, 4 treatment and management of ensuing complications may be delayed. A standard treatment remains to be established..$^{3,4}$

\section{Etiology}

Causes of cranial sinus thrombosis are extremely variable (table 1). In a majority of patients, a factor predisposing to thrombosis can be identified. ${ }^{10}$ Among those who are predisposed, a precipitating event, such as head injury or dehydration, can lead to cranial sinus thrombosis. More females of reproductive age are affected primarily because of oral contraceptive use ${ }^{11-17}$ and during pregnancy and puerperium. ${ }^{18,19}$ This sex predominance is absent in the elderly and children. ${ }^{20}$ Patient outcome often depends on the severity of symptoms at presentation; poor outcomes are associated with evidence of intracranial hypertension, large hemorrhagic infarcts, involvement of deep venous sinuses, and impaired consciousness. ${ }^{1,2,5,6}$

\section{Signs and Symptoms}

Severe headache is the common symptom in adults, with more than $90 \%$ affected by nonspecific head pain. Seizures are usually focal, and occur in up to $40 \%$ of patients, but may generalize or progress to status epilepticus. Focal or generalized seizures occur more often in cranial sinus thrombosis than in arterial stroke. ${ }^{2}$ If the thalami are affected, there may be behavioral symptoms (eg, delirium, amnesia, mutism). Classic unilateral hemispheric symptoms (eg, hemiparesis, aphasia) are rare. The patient may present in a coma, or with signs of herniation. In infectious cavernous sinus thrombosis, the presentation may include headache, fever, periorbital edema, proptosis, chemosis or extraoccular movement palsy. ${ }^{10}$

\section{Diagnosis}

The diagnosis depends strongly on a high index of suspicion and appropriate neuroimaging because of the nonspecific clinical symptoms. Classic CT findings include hemorrhagic infarcts that are inconsistent with any particular arterial vascular distribution, the hyperdense "delta sign" that becomes "empty delta sign" with contrast administration due to the presence of clot in the superior sagittal sinus. Careful review of the imaging is imperative to avoid missing the diagnosis. Adjustment of CT windows should be undertaken to facilitate visualization of subtle sinus thrombosis or venous hemorrhagic 

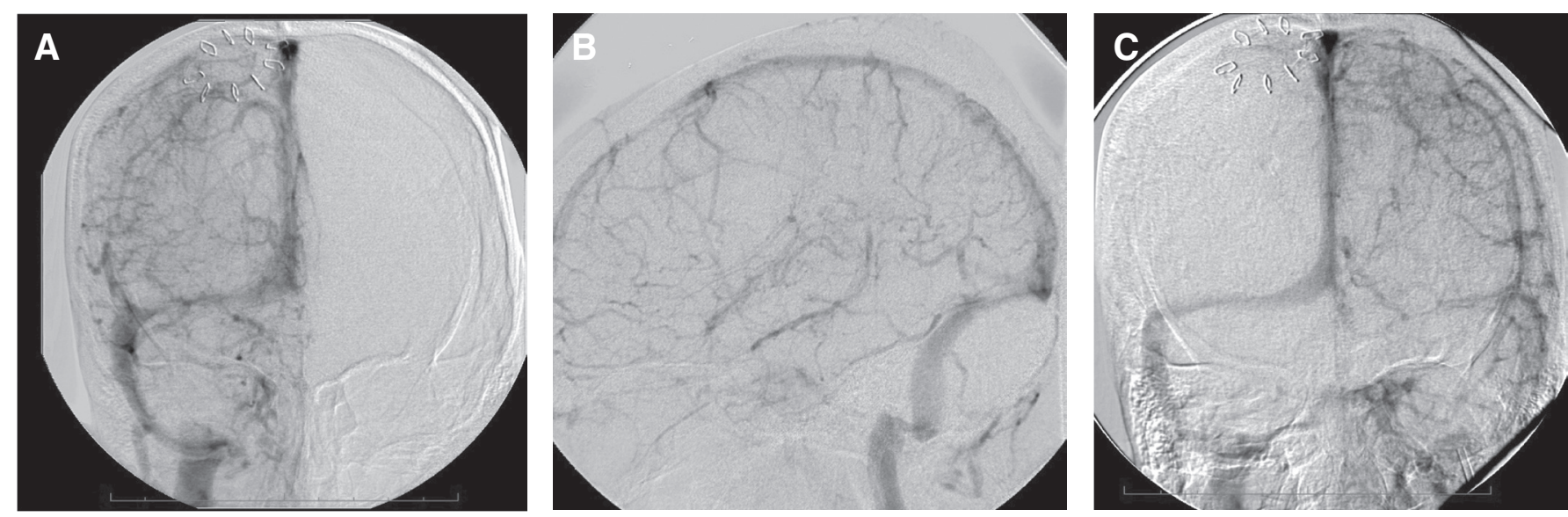

Figure 5. Cerebral angiography showing dramatic reconstitution of the superior sagittal sinus, right transverse and sigmoid sinuses, as well as right jugular vein in (A) anteroposterior and (B) lateral views. Consequent to overnight administration of tissue plasminogen activator into the superior sagittal sinus using a microcatheter, the flow in the left transverse-sigmoidjugular system was also successfully reestablished $(\mathrm{C})$ after mechanical thrombolysis using a Pronto V3 extraction catheter.

infarct. Depending on the age of the thrombus in the sinus, it appears hyperintense on T1- and T2-weighted magnetic resonance images (MRI). ${ }^{21,22}$ Noninvasive vascular imaging with CT or MRI to obtain angiographic or venographic studies may be significant for the absence of involved sinuses. Angiography is particularly useful when diagnosis remains uncertain following CT and MRI. The venous phase of cerebral angiography will demonstrate the absence of involved sinus. Dilated and corkscrew veins will be manifest upstream from the site of sinus occlusion. ${ }^{23}$

\section{Treatment}

Depending on the presentation of the patient, the initial management may consist of acute life-saving intervention, such as airway protection and management of intracranial pressure controlling measures with the administration of mannitol or hypertonic saline, ventriculostomy placement or hemicraniectomy. However, as demonstrated by our case, timely aggressive intervention can reverse the poor prognosis.

Thereafter, adequate hydration should be initiated and anticoagulation begun. ${ }^{2,24-28}$ Blood tests for hypercoagulopathy must be drawn prior to the initiation of anticoagulation. Coagulopathy work-up should be performed even when precipitating factors (eg, oral contraceptive usage, dehydration) appear obvious. Oral anticoagulation is continued for 3 months (target international normalized ratio 2.0-3.0) if the cranial sinus thrombosis is secondary to a reversible risk factor. It is administered for 6 to 12 months if the thrombosis is idiopathic or secondary to mild hereditary coagulopathy (eg, protein $\mathrm{C}$ or $\mathrm{S}$ deficiency, heterozygous factor $\mathrm{V}$ Leiden, prothrombin G20210A mutations). Long-term oral anticoagulation is used for idiopathic or severe hereditary coagulopathies. ${ }^{4,29}$

Surgical managementmay include decompressive craniectomy, endovascular intervention with locally infused rt-PA, or mechanical thrombolysis using microwires or available commercial devices.5,30-33 Information in the literature provides little guidance regarding optimum dosing of endovascularly-administered thrombolytic therapy for cranial sinus thrombosis. Significant variability also exists in patient selection for interventional management of cranial sinus thrombosis and the ideal thrombolytic agent and dosage. Although many case reports of endovascularly-administered thrombolytics have been published, minimal data are available to recommend a standard treatment. The heterogeneity of individual cases and availability of urokinase versus rt-PA during the past 10 to 15 years likely contribute to the variety of approaches in reported cases. In the absence of widely accepted standard therapy for dural sinus thrombolysis, we based our treatment strategy in part on our experience with intra-arterial thrombolysis.

\section{Chemical Thrombolysis}

Yamini et al ${ }^{34}$ reported on a patient with extensive cranial sinus thrombosis that did not improve after a $25 \mathrm{mg}$ bolus of rt-PA. A continuous infusion of rt-PA was administered at $1 \mathrm{mg}$ /hour for 19 hours, the patient recovered completely. In a series of nine patients ${ }^{32}$ treated with a maximum of $100 \mathrm{mg}$ daily of continuous $5 \mathrm{mg} /$ hour rt-PA infusion at the site of the thrombus after a $10 \mathrm{mg}$ bolus, no hemorrhagic complications were reported and all patients had good recovery at 3 months. In a study of 8 patients treated with either endovascular urokinase or rt-PA, Soleau et al ${ }^{35}$ reported increases in hemorrhagic complications but did not report doses of medications.

At our institution, we have considerable experience using combined intravenous and intra-arterial rt-PA for acute ischemic stroke based largely on the weight-based dosing used for the National Institute of Neurological Disorders and Stroke trial. We administered a maximum daily rt-PA dose of $90 \mathrm{mg}$ and infusion rate of $4 \mathrm{mg} /$ hour. We would likely use a lower rt-PA dose for the continuous infusion (0.5-1 mg/hour) 
Table 1. Etiology and risk factors for cranial sinus thrombosis.

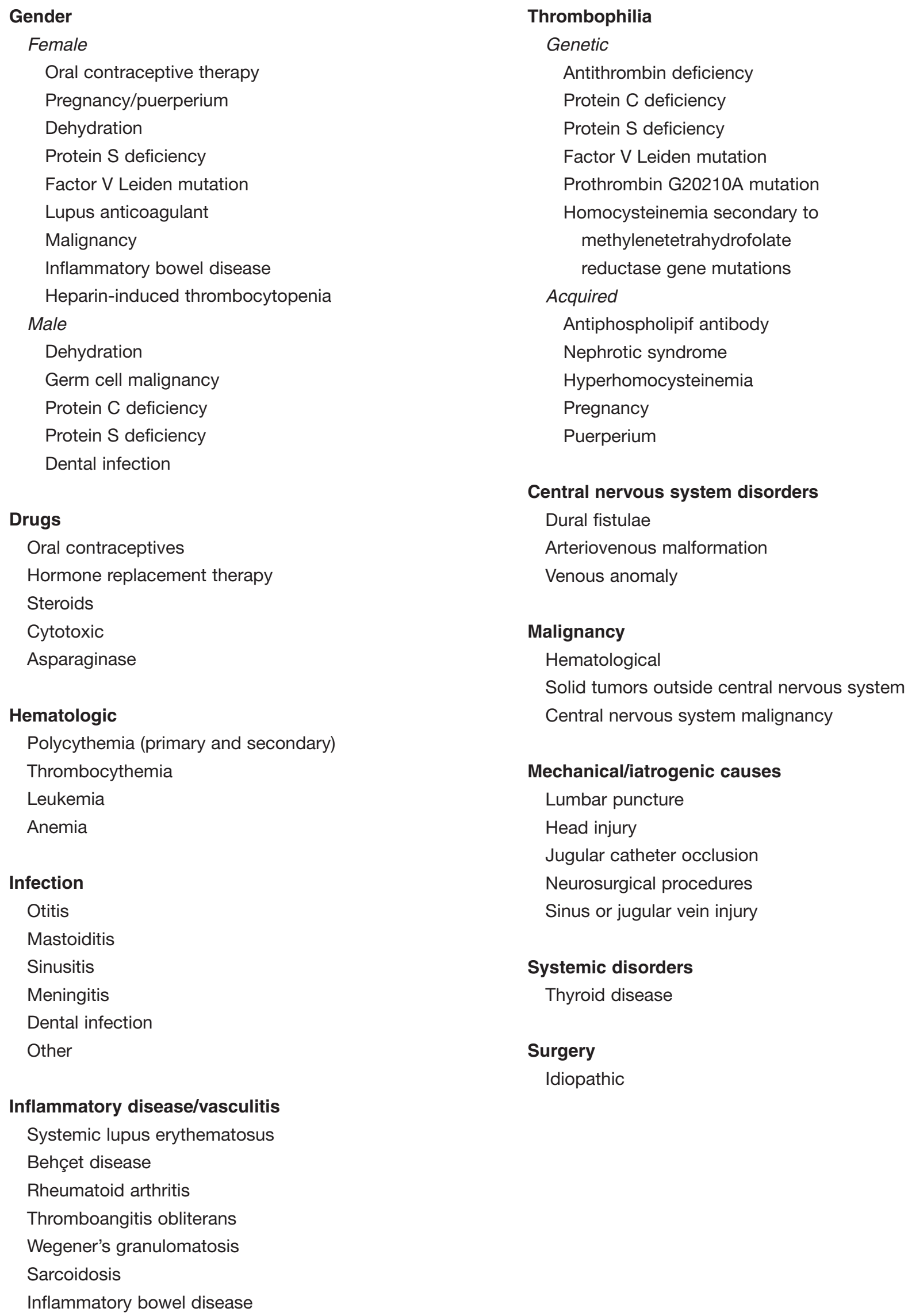

\section{Drugs}

Oral contraceptives

Hormone replacement therapy

Steroids

Cytotoxic

Asparaginase

\section{Hematologic}

Polycythemia (primary and secondary)

Thrombocythemia

Leukemia

Anemia

\section{Infection}

Otitis

Mastoiditis

Sinusitis

Meningitis

Dental infection

Other

\section{Inflammatory disease/vasculitis}

Systemic lupus erythematosus

Behçet disease

Rheumatoid arthritis

Thromboangitis obliterans

Wegener's granulomatosis

Sarcoidosis

Inflammatory bowel disease

Thrombophilia

Genetic

Antithrombin deficiency

Protein $\mathrm{C}$ deficiency

Protein S deficiency

Factor $\mathrm{V}$ Leiden mutation

Prothrombin G20210A mutation

Homocysteinemia secondary to methylenetetrahydrofolate reductase gene mutations

Acquired

Antiphospholipif antibody

Nephrotic syndrome

Hyperhomocysteinemia

Pregnancy

Puerperium

\section{Central nervous system disorders}

Dural fistulae

Arteriovenous malformation

Venous anomaly

\section{Malignancy}

Hematological

Solid tumors outside central nervous system

Central nervous system malignancy

\section{Mechanical/iatrogenic causes}

Lumbar puncture

Head injury

Jugular catheter occlusion

Neurosurgical procedures

Sinus or jugular vein injury

\section{Systemic disorders}

Thyroid disease

Surgery

Idiopathic 
or a higher infusion rate but a lower total dose. ${ }^{28,32-34}$ Since our patient, Tsai et al $^{36}$ reported on a series of 25 patients; 8 patients ( 6 with hemorrhage on initial CT) were treated with thrombectomy and a total rt-PA dose that ranged from 3 to $10 \mathrm{mg}$ infused at $1 \mathrm{mg} / \mathrm{minute}$. Five patients had symptomfree recovery and three had mild residual weakness.

\section{Devices}

After failure of commonly used devices for mechanical thrombolysis in our patient, we successfully tried a Pronto V3 catheter outside its realm of Food and Drug Administrationapproved indications as an extraction catheter for clots in the coronary and peripheral blood vessels. The spiral component of the Merci device often unravels during attempts at clot removal. The Pronto V3 proved to be sturdier with a design that eliminated the likelihood of collapse. Another device used for mechanical thrombolysis, the Angiojet, was bulky and could not be advanced beyond the sigmoid sinus, as previously described. ${ }^{37}$ The Pronto V3 was effective in aspiration of the venous sinus clot owing to its catheter size, simple design, and ease of use. After this first case, we have used the Pronto V3 in subsequent patients with the same observed benefits.

The occurrence of pulmonary embolism in our patient is a well-described complication. ${ }^{38-43}$ In a review of cranial sinus thrombosis cases from 1942 to 1990 , Diaz et al ${ }^{43}$ showed this combination to be particularly lethal, resulting in a mortality rate of $95.6 \%$. In these patients, pulmonary embolism appeared to be strongly suggestive of thrombus dislodgment from the cranial sinuses, particularly the superior sagittal sinus. Taking into account the increased predisposition to venous thrombosis because of oral contraceptive use in our patient, the possibility of pulmonary embolism consequent to small emboli from the lower extremities cannot be excluded despite the placement of an inferior vena cava filter. However, the extent of cranial sinus thrombosis made an intracranial thrombus origin a plausible source for pulmonary embolism. Our patient had a satisfactory outcome even with the potentially fatal combination of cranial sinus thrombosis and pulmonary embolism. It is important to address the underlying etiology because cranial sinus thrombosis may recur despite adequate anticoagulation. ${ }^{44}$ Survivors remain at risk of developing dural arterial venous malformations, which are believed to represent recanalization following cranial sinus thrombosis in adults. ${ }^{45}$

\section{Conclusion}

Effective management of multiple cranial sinus thrombosis requires a combination of medical and surgical interventions. Vigilance is required to ensure early diagnosis and timely intervention for associated complications. The collaborative effort of our multidisciplinary team and the novel use of a thrombectomy catheter contributed to the successful outcome in our patient.

\section{Acknowledgments}

This research was performed at The Neuroscience Institute, University of Cincinnati College of Medicine, Cincinnati, Ohio. The authors thank Marshfield Clinic Research Foundation for its support through the assistance of Marie Fleisner and Alice Stargardt in the preparation of this manuscript.

\section{References}

1. Mehraein S, Schmidtke K, Villringer A, Valdueza JM, Masuhr F. Heparin treatment in cerebral sinus and venous thrombosis: patients at risk of fatal outcome. Cerebrovasc Dis 2003; 15:17-21.

2. Ferro JM, Canhão P, Stam J, Bousser MG, Barinagarrementeria F; ISCVT Investigators. Prognosis of cerebral vein and dural sinus thrombosis: results of the International Study on Cerebral Vein and Dural Sinus Thrombosis (ISCVT). Stroke 2004;35:664-670.

3. Bousser MG. Cerebral venous thrombosis: nothing, heparin, or local thrombolysis? Stroke 1999;30:481-483.

4. Einhäupl K, Bousser MG, de Bruijn SF, Ferro JM, Martinelli I, Masuhr F, Stam J. EFNS guideline on the treatment of cerebral venous and sinus thrombosis. Eur J Neurol 2006;13:553-559.

5. Masuhr F, Mehraein S. Cerebral venous and sinus thrombosis: patients with a fatal outcome during intravenous doseadjusted heparin treatment. Neurocrit Care 2004;1:355-361.

6. De Bruijn SF, de Haan RJ, Stam J. Clinical features and prognostic factors of cerebral venous and sinus thrombosis in a prospective series of 59 patients. J Neurol Neurosurg Psychiatry 2001;70:105-108.

7. Spearman MP, Jungreis CA, Wehner JJ, Gerszten PC, Welch WC. Endovascular thrombolysis in deep cerebral venous thrombosis. AJNR Am J Neuroradiol 1997;18:502-506.

8. Bousser MG, Chiras J, Bories J, Castaigne P. Cerebral venous thrombosis-a review of 38 cases. Stroke 1985;16:199-213.

9. Einhäupl KM, Villringer A, Haberl RL, Pfister W, Deckert M, Steinhoff H, Schmiedek P. Clinical spectrum of sinus venous thrombosis. In: Einhäupl KM, Kempski O, Baethmann A, editors. Cerebral sinus thrombosis: experimental and clinical aspects. New York: Plenum Press; 1990:149-156.

10. Stam J. Thrombosis of the cerebral veins and sinuses. N Engl J Med 2005;352:1791-1798.

11. Martinelli I, Sacchi E, Landi G, Taioli E, Duca F, Mannucci PM. High risk of cerebral-vein thrombosis in carriers of a prothrombin-gene mutation and in users of oral contraceptives. N Engl J Med 1998;338:1793-1797.

12. Atkinson EA, Fairburn B, Heathfield KW. Intracranial venous thrombosis as complication of oral contraception. Lancet 1970;1:914-918.

13. Fairburn B. Intracranial venous thrombosis complicating oral contraception: treatment by anticoagulant drugs. Br Med J 1973;2:647.

14. Dindar F, Platts ME. Intracranial venous thrombosis complicating oral contraception. Can Med Assoc J 1974;111:545-548.

15. Irey NS, Manion WC, Taylor HB. Vascular lesions in women taking oral contraceptives. Arch Pathol 1970;89:1-8.

16. Plowright C, Adam SA, Thorogood M, Beaumont V, Beaumont JL, Mann JI. Immunogenicity and the vascular risk of oral contraceptives. Br Heart J 1985;53:556-561.

17. Inman WH, Vessey MP. Investigation of deaths from pulmonary, coronary, and cerebral thrombosis and embolism in women of child-bearing age. Br Med J 1968;2:193-199.

18. Cantú C, Barinagarrementeria F. Cerebral venous thrombosis associated with pregnancy and puerperium. Review of 67 cases. Stroke 1993;24:1880-1884. 
19. Lanska DJ, Kryscio RJ. Risk factors for peripartum and postpartum stroke and intracranial venous thrombosis. Stroke 2000;31:1274-1282.

20. deVeber G, Andrew M, Adams C, Bjornson B, Booth F, Buckley DJ, Camfield CS, David M, Humphreys P, Langevin P, MacDonald EA, Gillett J, Meaney B, Shevell M, Sinclair DB, Yager J; Canadian Pediatric Ischemic Stroke Study Group. Cerebral sinovenous thrombosis in children. N Engl $\mathbf{J}$ Med 2001;345:417-423.

21. Dormont D, Anxionnat R, Evrard S, Louaille C, Chiras J, Marsault C. MRI in cerebral venous thrombosis. J Neuroradiol 1994;21:81-99.

22. Isensee C, Reul J, Thron A. Magnetic resonance imaging of thrombosed dural sinuses. Stroke 1994;25:29-34.

23. Bousser MG, Ross Russell R. Cerebral venous thrombosis. Vol. 1. London, UK: WB Saunders; 1997:175.

24. Einhäupl KM, Villringer A, Meister W, Mehraein S, Garner C, Pellkofer M, Haberl RL, Pfister HW, Schmiedek P. Heparin treatment in sinus venous thrombosis. Lancet 1991; 338:597-600.

25. de Bruijn SF, Stam J. Randomized, placebo-controlled trial of anticoagulant treatment with low-molecular-weight heparin for cerebral sinus thrombosis. Stroke 1999;30:484-488.

26. Strupp M, Covi M, Seelos K, Dichgans M, Brandt T. Cerebral venous thrombosis: correlation between recanalization and clinical outcome--a long-term follow-up of 40 patients. J Neurol 2002;249:1123-1124.

27. Baumgartner RW, Studer A, Arnold M, Georgiadis D. Recanalisation of cerebral venous thrombosis. J Neurol Neurosurg Psychiatry 2003;74:459-461.

28. Khan SH, Abruzzo TA, Sangha KS, Ringer AJ. Use of antiplatelet, anticoagulant and thrombolytic agents in endovascular procedures. Contemp Neurosurg 2007;29:1-7.

29. Büller HR, Agnelli G, Hull RD, Hyers TM, Prins MH, Raskob GE. Antithrombotic therapy for venous thromboembolic disease: the Seventh ACCP Conference on Antithrombotic and Thrombolytic Therapy. Chest 2004;126(3 Suppl): 401S-428S.

30. Higashida RT, Helmer E, Halbach VV, Hieshima GB. Direct thrombolytic therapy for superior sagittal sinus thrombosis. AJNR Am J Neuroradiol 1989;10(5 Suppl):S4-S6.

31. Niwa J, Ohyama H, Matumura S, Maeda Y, Shimizu T. Treatment of acute superior sagittal sinus thrombosis by t-PA infusion via venography--direct thrombolytic therapy in the acute phase. Surg Neurol 1998;49:425-429.

32. Kim SY, Suh JH. Direct endovascular thrombolytic therapy for dural sinus thrombosis: infusion of alteplase. AJNR Am J Neuroradiol 1997; 18:639-645.

33. Frey JL, Muro GJ, McDougall CG, Dean BL, Jahnke HK. Cerebral venous thrombosis: combined intrathrombus rtPA and intravenous heparin. Stroke 1999;30:489-494.

34. Yamini B, Loch Macdonald R, Rosenblum J. Treatment of deep cerebral venous thrombosis by local infusion of tissue plasminogen activator. Surg Neurol 2001;55:340-346.

35. Soleau SW, Schmidt R, Stevens S, Osborn A, MacDonald JD. Extensive experience with dural sinus thrombosis. Neurosurgery 2003;52:534-544.

36. Tsai FY, Kostanian V, Rivera M, Lee KW, Chen CC, Nguyen $\mathrm{TH}$. Cerebral venous congestion as indication for thrombolytic treatment. Cardiovasc Intervent Radiol 2007;30:675-687.

37. Baker MD, Opatowsky MJ, Wilson JA, Glazier SS, Morris PP. Rheolytic catheter and thrombolysis of dural venous sinus thrombosis: a case series. Neurosurgery 2001;48:487-493.

38. Corvol JC, Oppenheim C, Manaï R, Logak M, Dormont D, Samson Y, Marsault C, Rancurel G. Diffusion-weighted magnetic resonance imaging in a case of cerebral venous thrombosis. Stroke 1998;29:2649-2652.
39. Cramer M. Ein Fall von marantischer Thrombose im Sinus longitudinalis und in Lungenvene Diss München; 1902.

40. Halff J. Die marantische Thrombose der Duralsinus. Inaug Diss Basel; 1904.

41. Hyland HH. Intracranial venous thrombosis in the puerperium. J Am Med Assoc 1950;142:707-710.

42. Thikötter J. Über einen Fall von marantischer Sinusthrombose im Puerperium. Bremen. Inaug Diss Munchen; 1891.

43. Diaz JM, Schiffman JS, Urban ES, Maccario M. Superior sagittal sinus thrombosis and pulmonary embolism: a syndrome rediscovered. Acta Neurol Scand 1992;86:390-396.

44. Lin JH, Kwan SY, Wu D. Cerebral venous thrombosis initially presenting with acute subarachnoid hemorrhage. J Chin Med Assoc 2006;69:282-285.

45. Morris P. Dural arteriovenous malformations. Interventional and endovascular therapy of the nervous system: a practical guide. 1st ed. New York: Springer-Verlag; 2002. 159-176.

\section{Author Affiliations}

Shah-Naz Hayat Khan, MD, FRCSC $\#, \ldots, 1$

Opeolu Adeoye, MD*;

Todd Anthony Abruzzo, MD';

Lori A. Shutter, MD, PT*, ${ }^{*}$;

Andrew Joel Ringer, $M D^{*}, \neq, \xi$;

\#Department of Neurosurgery, Marshfield Clinic

Marshfield, Wisconsin

The Neuroscience Institute

*Division of Neurosciences Intensive Care,

tDepartment of Neuroradiology, and

tDepartment of Neurosurgery,

University of Cincinnati College of Medicine,

Cincinnati, Ohio

§The Mayfield Clinic

Cincinnati, Ohio

IPresent address:

Cerebrovascular and Skull Base Surgery Program

Department of Surgery, Division of Neurosurgery

St. Louis University, School of Medicine

St. Louis, Missouri 